This item was submitted to Loughborough's Research Repository by the author.

Items in Figshare are protected by copyright, with all rights reserved, unless otherwise indicated.

\title{
Stressors and creativity in industrial design practice
}

\section{PLEASE CITE THE PUBLISHED VERSION}

https://designinnovationmanagement.com/pub/adim2019_proceedings.pdf

\section{PUBLISHER}

Design Research Society

\section{VERSION}

AM (Accepted Manuscript)

\section{PUBLISHER STATEMENT}

This work is made available according to the conditions of the Creative Commons Attribution-NonCommercialNoDerivatives 4.0 International (CC BY-NC-ND 4.0) licence. Full details of this licence are available at: https://creativecommons.org/licenses/by-nc-nd/4.0/

\section{LICENCE}

CC BY-NC-SA 4.0

\section{REPOSITORY RECORD}

McCardle, John, Samuel Dempsey, and Max Humberstone. 2019. "Stressors and Creativity in Industrial Design Practice". figshare. https://hdl.handle.net/2134/37383. 


\title{
Stressors and creativity in Industrial Design practice
}

\author{
McCARDLE John*; DEMPSEY Samuel and HUMBERSTONE Max \\ Loughborough Design School, Loughborough University, UK
}

\begin{abstract}
Current literature suggests that stress influences creativity, however further research is required concerning this relationship with a focus on education. Current views are clearly divided on whether any negative effects on creativity are more dictated by environmental stressors or the reactions of individuals whilst under stress. For this study, participants completed a questionnaire comprising of a perceived stress scale and thematic questions, to give an indication of whether they were more influenced by environmental stressors or their individual reactions to stress. Two Torrance tests of creativity were conducted to assess creativity over a two-week period as time pressures increased. The results suggested that participants who identified as being more affected by their own negative reactions to stress displayed a lower calibre of creativity when time-pressure increased, whereas the participants who were suggested to be more influenced by their environment remained at a relatively constant perceived level of creativity.
\end{abstract}

Keywords: Creativity, Stress, Environment, Reactive, Industrial Design

\section{Introduction}

Within educational and professional practice environments, an atmosphere of pressure and stress is commonplace. At a time when innovation and creativity is highly valued, research on the imposed external and internal stressors that may limit this value are highly relevant. The debate continues as whether the effects of stress in relation to creativity are influenced more by the environment, or the individual's possible negative reaction to stress. Many difficulties exist in the study of creativity in design; its definition, protocol observation of action and levels of attainment are highly interpretable and subjective. Nevertheless, while creativity as an innate human propensity is considered to be an emotionally enjoyable act, other external and internal factors are known to depress motivation and drive anxiety, destroy confidence and elevate stress levels.

...artistic activity is a route to human well-being both for people who do not have mental disorders and who want to get the most out of life and for people with minor and major disorders who can find both solace and a way to a satisfying and meaningful life through artistic activity. Maybe those who believe there is a link between mental illness and creative genius are right - though I and others don't think so. But it's for sure that creativity has much to contribute to mental health and human well-being. (Friedman, 2014)

The aim of this small scale study was to investigate the extent to which stress affects creativity within a group of Industrial Design students and to examine whether any adverse effects on creativity are suggested to be driven by environmental stressors or the student's adverse reaction to stress. To gain these insights we classified students into groups who were identified as having potential to be negatively affected by either a stressful environment or negative reactions to inherent stresses, and measured the extent to which individuals perceived they were stressed during a period of work. Abridged Torrance tests of creativity on these groups were repeated to examine if either group suffered a greater negative effect on their creativity as time pressure increased. By gaining insight into any adverse effects on creativity influenced by environmental stressors or the Design student's possible adverse reaction to stress, we aim to develop support strategies for designers in education and professional practice. 


\section{Literature review}

According to investment theory, creativity is underpinned by; intellectual abilities, knowledge, styles of thinking, personality, motivation, and environment (Sternberg, 2010). In the last 50 years a large body of work has evolved around the relationship between the characteristics of individuals and their creative performance. Research from Oldham \& Cummings (1996) and Shalley, Zhou, \& Oldham (2004) for instance, conclude that personality, cognitive style, and knowledge, are positively related to worker inventiveness.

The term Creative Confidence has become an important factor in nurturing creativity and understanding a person's belief in their own ability to successfully complete a creative task (Phelan \& Young, 2003). As such, Self-efficacy provides a foundation for creative confidence as an innate belief in one's own ability to complete a certain task (Bandura, 1993). Individuals with a higher level of self-efficacy have been shown to exhibit greater persistence in overcoming obstacles (ibid.), and demonstrate elements of designerly play when approaching problem tasks. Designerly play can be considered a form of creative exploration without the fear of getting things wrong. Indeed, risk-taking has been shown to be one of the most significant resultants of play. It is important for any project involving creativity that those involved are prepared to take risks (Kelley, 2001), however in education such risks are often avoided (McCardle, Huskisson \& Perry, 2018).

The causes and effects of the factors associated with creativity and its relationship with stress related issues is broad and widely known to be convoluted. But the consequences to and impact upon personal creative growth in $\mathrm{HE}$, and further on into continual professional development for practitioners, should be of more concern. Not only for reasons of achievement, but in safeguarding personal wellbeing. More recently, there has been an acknowledgement of the importance of workload pressures, but an appropriate working environment as a component in supporting and nurturing creativity has also featured strongly.

\section{The Environment}

In 1979 Teresa Amabile published work that conveyed how evaluative environments can often lead to diminished creative output from students. Amabile conducted experiments that entailed leading a creativitybased task with two groups of art students. One group's members were told that work would be evaluated, whilst the other was not. Within the context of creativity defined for the work, Amabile concluded that the group members told they were being evaluated displayed significantly less creativity. It was consequently held as an example of where the stress of the environment can directly lead to a negative impact on creativity (Amabile, 1979). In continuing work, Amabile, Hadley, \& Kramer (2002) examined in more detail environmental effects on creativity of 177 employees across 22 companies whilst under time pressure and stress. Their findings showed that an environment rich in time pressures resulted in multiple possible outcomes for creativity, both positive and negative. For example, an environment rich in time pressures that had a fragmented schedule, would likely produce a low creative output, surmised as being due to the presence of stress caused by a lack of allocated time available to seriously negotiate a task. The result is summarized in the time pressure/creativity matrix of Figure 1. 


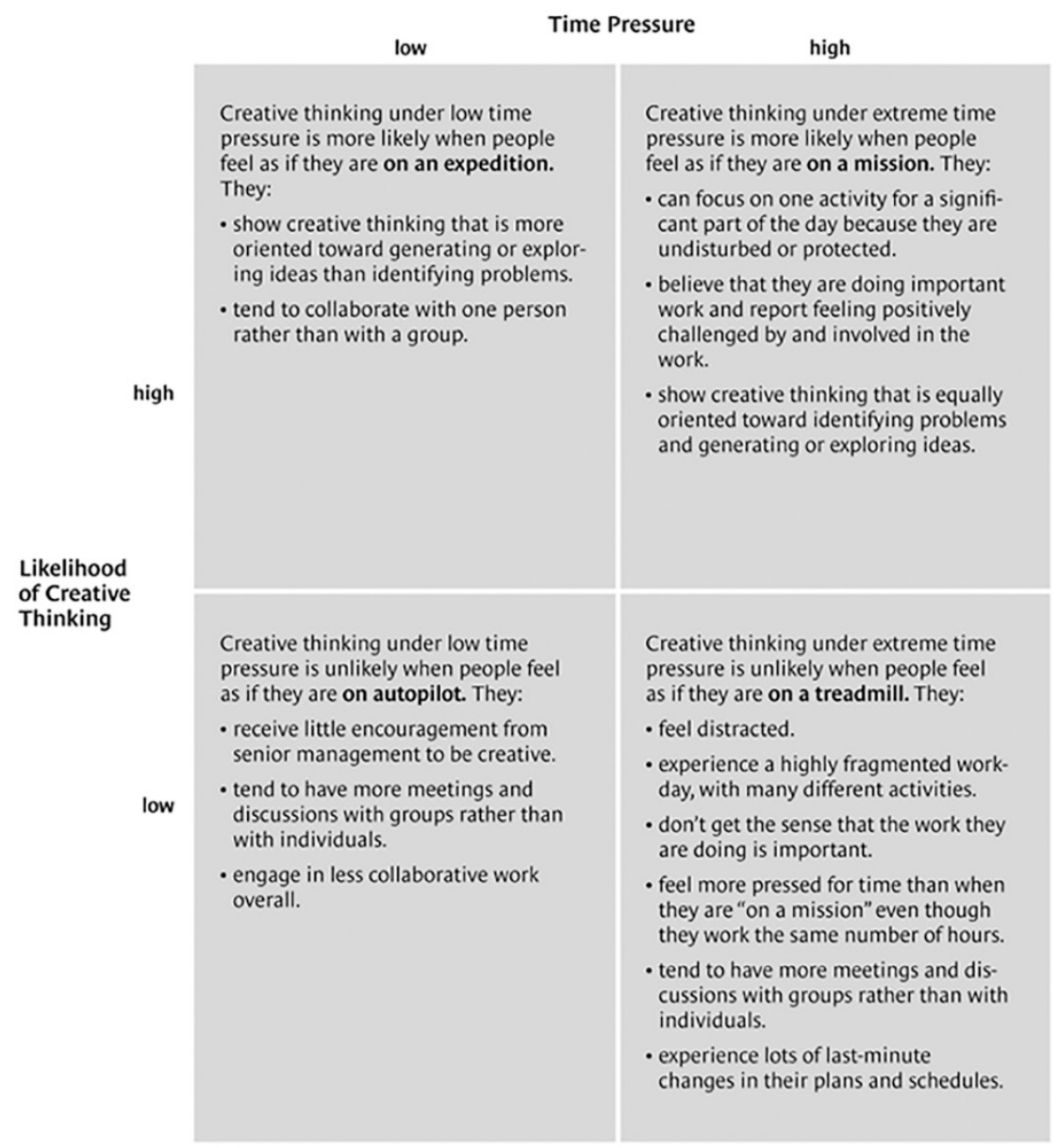

Figure 1: Time Pressure/ Creativity Matrix (T. Amabile et al., 2002)

However, the methodology employed here, whilst relevant, didn't attempt to measure creativity externally but relied on individual's self-perception and peer review.

Byron, Khazanchi, \& Nazarian, (2010), have provided a meta-view of creativity and stress research. They concluded that stress is potentially both a contributor and a limit to creativity. Their overview confirms the existing arguments concerning the direct relationship between creativity and stress. The long held view of Wilke, Gmelch, \& Lovrich (1985), is that this relationship is an inverted U-shape, in line with the YerkesDodson Law (R. A. Cohen, 2011). That is, low stress results in low creativity, but which increases for a growth in stress, but at some point decreases again as stress continues to grow (see Fig. 2). Some studies however have observed the opposite. In certain disciplines such as engineering, increased pressure beyond that that would be generally acceptable to many, has been observed to increase creativity (Andrews \& Farris, 1972). What decides the effect is down to the context of stress; for example, if there is high level of pressure for delivering success then this may produce stress in combination with high levels of anxiety, which was found to be detrimental to creativity. Byron et al. (op.cit) suggest that the uncontrollable aspects of environmental based stressors, such as deadlines, course requirements and expectations that are perceived to be outside of a person's control are detrimental. Moreover, environments high in external evaluations decrease creativity. Of course, in education or in professional practice, this raises a serious dilemma. The question also remains as to whether any adverse effects on creativity are driven more by environmental stressors or personal adverse reaction to stress. 


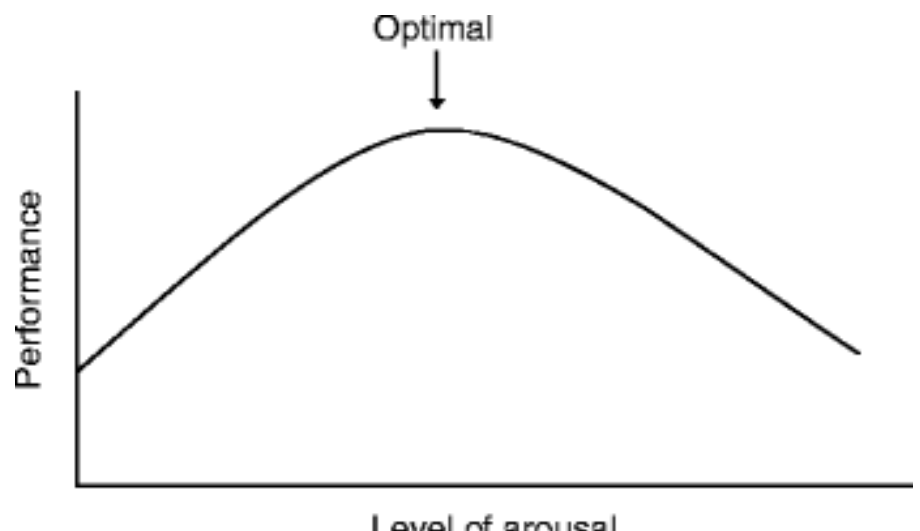

Figure 2: Yerkes \& Dodson (1908) cited from (R. A. Cohen, 2011)

Determining a consistent method of assessing creativity is exceptionally difficult as the environmental conditions and cognitive personalities of individuals vary widely. However, the use of the Torrance Test of Creative Thinking (TTCT) (Wallach, 1968) is common. Using this test, the relationship between time pressure and creativity has been investigated by Hsiao, Wang, \& Chen (2015), which concluded that long-term environmental stress and pressure induced by high workload and high pressure to succeed in a high evaluation environment, is incompatible with creativity. This is a view further supported by research undertaken by Ding, Tang, Tang, \& Posner (2014), again using the TTCT, which found that Integrative Body-Mind Training (IBMT) breathing exercise as part of an environment that promotes calm thinking and removing time pressure, aids creativity, reduces stress and promotes creativity.

The view that the environment is primarily responsible for negative effects of stress on creative ability is, in part, agreed with by Nguyen \& Zeng (2012). Their work suggests that mental stresses are directly related to the contextual and environmental workload of the specific design task, ergo, the limit of the creative potential is highly correlated to the size of the design task at hand. Importantly they further suggested that the designer's mental capacity whilst dealing with stress is also crucial in defining the overall effect of stress.

\section{Reactive influence}

Perhaps the most prominent counter view to the idea that the environment dictates the effects of stress on creativity is that creativity is more dictated by an individual's internal negative reaction to that stress. Ceci \& Kumar (2016) maintain the view that positive and negative emotions are at play and unavoidable when engaging with creative tasks and that the key to maintaining a creative output throughout stressful periods lie within the individuals own ability to react to stress positively. With links specifically to motivation, their study used the Griffin and McDermott creativity checklist (Griffin \& McDermott, 1998) to assess the creative accomplishments of a group of students self-reporting on motivation, happiness, creativity, and perceived stress. Amabile's 'Work Preference Inventory' (T. M. Amabile, 1983) was also used specifically to determine that motivation was the defining factor. Results suggested that the individual's reaction to stress dictated the influence more so than the environment. For example, two students who were experiencing the same amount of time pressure on a given piece of work reacted differently. The work concluded that an individual who takes the pressure as a motivator may perform more creatively, whereas the other may take the pressure as evaluative and perform less creatively. This work is key in introducing the theme of negative effects on creativity as not being derived entirely from environmental stressors, but also from individual reactions to stress.

This view has been further validated by Gutnick, Walter, Nijstad, \& De Dreu (2012) who formed two propositions based on literature surrounding stress and creativity:

1) High work pressure strengthens "threat appraisals" = reducing creativity.

2) High work pressure enhances "challenge appraisals" = enhancing creativity.

Therefore the concept of varying reactions to stress, whether positive or negative, plays a major part in defining the resulting effect. This furthers the notion that an individual can feel threatened by work (Liu, 
Wang, Ren, \& Liu, 2017) and that an undelying motivation commonly falls victim to stress, with the consequential impact on the overall quality of a creative output.

The perception of formality can also contribute to the evaluative perceptions drawn by an individual. An investigation where participants were set tasks in a hypothetical scenario, acting as Human Resources directors, showed that the delivery or presentation of the task to the participants was influential for the motivation in creative tasks. When the delivery was formal and controlling, there was significantly less creativity observed (Shalley \& Perry-Smith, 2001). The perception of confrontation or conflict also poses a risk to creativity. Work by (Carnevale \& Probst, 1998) concluded that individuals who are expecting conflict rather than cooperation, are less likely to attain a higher level of creativity.

Reactive influence is therefore driven by the key aspect of innate perspective and the personality and behaviour of the individual. Sung \& Choi (2009) found that extrinsic motivation contrastingly effected creativity for participants with 'agreeableness' or 'openness' traits. Individuals with high openness to experience seemed to perform better when they were motivated to complete the task through gaining rewards and acknowledgement for their performance. For people who were high in the agreeableness, extrinsic motivation was not beneficial for their creative performance. Given that agreeable individuals care about others and tend to prefer agreeing with other's opinions to avoid confrontation, their creative performance are considered to be further decreased if they are concerned about rewards, compensation, or other's evaluation of their performance. In contrast, agreeableness was positively associated with creativity when the person had low extrinsic motivation, and thus they were less concern about other's opinions. This could possibly indicate that agreeable people are less likely to be influenced by the social or physical elements of a given setting.

A dual-pathway model has been suggested as a way to identify two routes to creative outcomes (Baas \& Roskes et al, 2013). Through defining a flexible information intake and a cognitive persistence intake, observations here indicated that individuals who maintain both these pathways through high pressure periods are less likely to have their creativity limited. In short, having personality traits of open-mindedness and dogged determination is more likely to result in creativity.

Finally, an individual's perception of support in being creative is also an integral factor for defining the relation between stress and creativity. Evidence suggests that innovative performances can be lower when an individual's perception of support in driving innovation is low (Leung et al., 2011). The lack of perceived support for an individual may lead to an apathetic attitude towards their creative tasks, drawing parallels to the motivation argument put forward by Ceci \& Kumar (2016).

\section{Methodology}

The method for this work was conducted in three sections as shown in Table 1. Ethical clearance was gained before making any contact with participants for the study. An informed consent form was used to ensure participants were willing to take part in the research which also outlined the rules applied around anonymity of data collection and the purpose of the study. Participants were reminded that they were free to remove themselves from the study at any time.

The questionnaire consisted of two sections. The first section utilised the standardised Perceived Stress Scale questionnaire (PSS-14) to indicate the extent to which the participants perceived their current stress levels, (Cohen et al., 1983). The 14 questions asked the user about emotions and scenarios over the previous month, as a 4-point Likert scale format. The direct scoring system was used to determine the level of a participant's stress as ordinal data. 


\begin{tabular}{lll}
\hline \multicolumn{1}{c}{ Methodology } & \multicolumn{1}{c}{ Purpose } & \multicolumn{1}{c}{ Limitations } \\
\hline $\begin{array}{l}\text { Questionnaire Part 1 (PSS) } \\
\text { (S. Cohen et al., 1983) }\end{array}$ & $\begin{array}{l}\text { The Perceived Stress Scale section } \\
\text { quantitatively assesses the extent } \\
\text { to which students are stressed }\end{array}$ & $\begin{array}{l}\text { The possibility of missing an } \\
\text { interesting insight that can } \\
\text { potentially be achieved through } \\
\text { focus groups or interviews. }\end{array}$ \\
\hline Questionnaire Part 2 & $\begin{array}{l}\text { To group participants based on } \\
\text { their leaning towards being } \\
\text { affected more by environmental } \\
\text { stressors or reactive stressors }\end{array}$ & $\begin{array}{l}\text { Small group size. An online } \\
\text { questionnaire, with the possibility } \\
\text { of participants not fully } \\
\text { understanding the questions. }\end{array}$ \\
\hline $\begin{array}{lll}\text { Abridged Figural Torrance Test of } \\
\text { Creative Thinking }\end{array}$ & $\begin{array}{l}\text { Picture construction creativity } \\
\text { test. Suited to visual creativity of } \\
\text { industrial design students. }\end{array}$ & $\begin{array}{l}\text { Preparations are needed. Time } \\
\text { consuming to conduct. }\end{array}$ \\
\hline
\end{tabular}

The second section comprised 10 questions formed from the references provided in Figure 3. The questions were chosen to characterise the participants to facilitate grouping for the abridged figural TTCT. Five of these questions were linked to environmental stressors affecting creativity, and 5 were linked to negative reactions to stress affecting creativity (See Fig. 3). The responses to these questions determined the group membership, based on leanings towards either environmental or reactive affecters.

1) Long term demand for creativity (Hsiao et al., 2015)
2) Disjointed timetable (Amabile et al., 2002)
3) The requirements are too large (Nguyen \& Zeng, 2012
4) No time to relax (Ding et al., 2014)
5) Evaluation/ marking of work (Byron et al., 2010)

1) Diminished motivation(Ceci \& Kumar, 2016)

2) Lack of mental stamina (Baas et al., 2013)

3) Work is a threat (Gutnick et al., 2012)

4) Formal Perceptions (Shalley \& Perry-Smith, 2001)

5) Perceived support (Leung et al., 2011)
More affected by environmental stressors

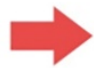

More affected by individual reactions to stress

Figure 3: Thematic Grouping for Questionnaire

All sections were piloted with undergraduate Design students not participating in the full study. Figural drawing tests were limited to 6.5 minutes in the baseline and repeat tests; the duration of which was optimised from the pilot. The researcher was present to explain the test to the participants and answer any questions. The baseline and repeat tests were conducted with the participants over a 3-day duration in week 4 and 6 of a single semester. This was greatest amount of time possible between the baseline and repeat tests to measure the possible effects on creativity defined by time pressures increasing.

The creative task consisted of a simple geometric configuration from which the participants were asked to reconfigure as imaginatively as they could, within the time limit of 6.5 minutes. The output of the creative tasks was assessed on a numerical system whereby a mark between 1 and 5 was awarded for each section, for each participant's response, in line with the following criteria;

- $\quad$ Fluency: The number of valid responses offered based on the starting geometry.

- Flexibility: The number of dramatic shifts from one theme to another throughout the responses.

- Originality: The infrequency of themes offered relative to themes present in the rest of the participants.

- Elaboration: The graphical detail in each response. 


\section{Results}

Seventeen total responses to the two-stage questionnaire from undergraduate Design students were completed. Table 3 shows the participants PSS score and leanings towards either environmental factors or individual reactions negatively affecting their creativity. Participants who were suggested to be more influenced by environmental stressors formed GROUP E and participants who were suggested to be more influenced by their individual negative reactions to stress formed GROUP R.

Of the 17 who participated in the questionnaire, 5 participants chose not to take part in any further stages of the investigation. From the remaining 12 participants, 10 were chosen based on two factors; those who scored highest on the PSS section, and those who sided most strongly with either environmental factors or individual reactions negatively affecting their creativity. Participants 9 and 14 gave an inconclusive result.

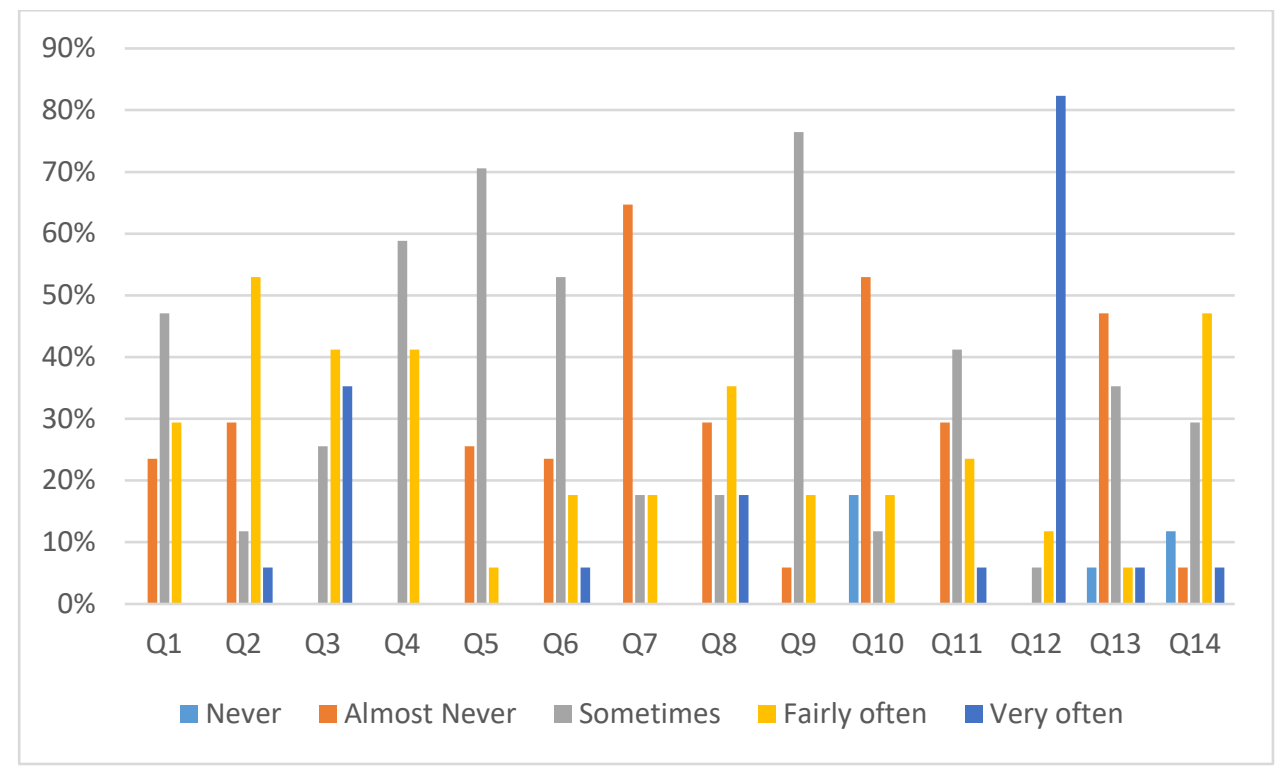

Figure 3: Overall PSS responses to Q1-14

Questions 1-14 for the Perceived Stress Scale:

In the last Month how often have you....

Q1 - been upset because of something that happened unexpectedly?

Q2 - felt that you were unable to control the important things in your life?

Q3 - felt nervous and stressed?

Q4 - dealt successfully with irritating life hassles?

Q5 - felt you were coping well with important changes in your life?

Q6 - felt confident in your ability to handle your personal problems?

Q7 - felt that things were going your way?

Q8 - found that you could cope with all the things you have had to do?

Q9 - been able to control irritations in your life?

Q10 - felt you were on top of things?

Q11 - been angered because of things that were out of your control?

Q12 - found yourself thinking about the things you have to accomplish?

Q13 - been able to control the way you spend your time? 
Q14 - felt difficulties were piling up so high that you could not overcome them?

Table3. Results of PSS Questionnaire

\begin{tabular}{|c|c|c|}
\hline Participant & $\begin{array}{c}\text { PSS Score } \\
\text { Q1-14 }\end{array}$ & $\begin{array}{c}\text { Environment / Reaction } \\
\text { Q14-24 }\end{array}$ \\
\hline 1 & 36 & $E$ \\
\hline 2 & 34 & $\mathrm{R}$ \\
\hline 3 & 32 & $\mathrm{R}$ \\
\hline 4 & 34 & $E$ \\
\hline 5 & 35 & $\mathrm{E}$ \\
\hline 6 & 34 & $\mathrm{R}$ \\
\hline 7 & 36 & $\mathrm{R}$ \\
\hline 8 & 18 & $E$ \\
\hline 9 & 21 & Inconclusive \\
\hline 10 & 34 & $E$ \\
\hline 11 & 36 & $E$ \\
\hline 12 & 35 & $\mathrm{R}$ \\
\hline 13 & 37 & $\mathrm{R}$ \\
\hline 14 & 35 & Inconclusive \\
\hline 15 & 36 & $E$ \\
\hline 16 & 27 & $\mathrm{R}$ \\
\hline 17 & 31 & $\mathrm{E}$ \\
\hline
\end{tabular}

The results given in Table 4 illustrate the difference in PSS scores between the two groups across both phases. Questions 10-24 for Environmental/Reactive response:

Q15 - Do you think you have become more or less creative as the year has gone on?

Q16 - How motivated do you feel to work each day?

Q17 - Has your work often been interrupted by compulsory sessions?

Q18 - How often do you take breaks throughout the day?

Q19 - 'I feel on top of my workload most of the time'?

Q20 - I want to do as well for my degree? Or I want to challenge myself and achieve?

Q21- How often do you have time for personal activities?

Q22 - When do you feel most creative?

Q23 - I am at university to, a) be evaluated or b) learn new skills

Q24 - Do you fell more creative after meetings? 


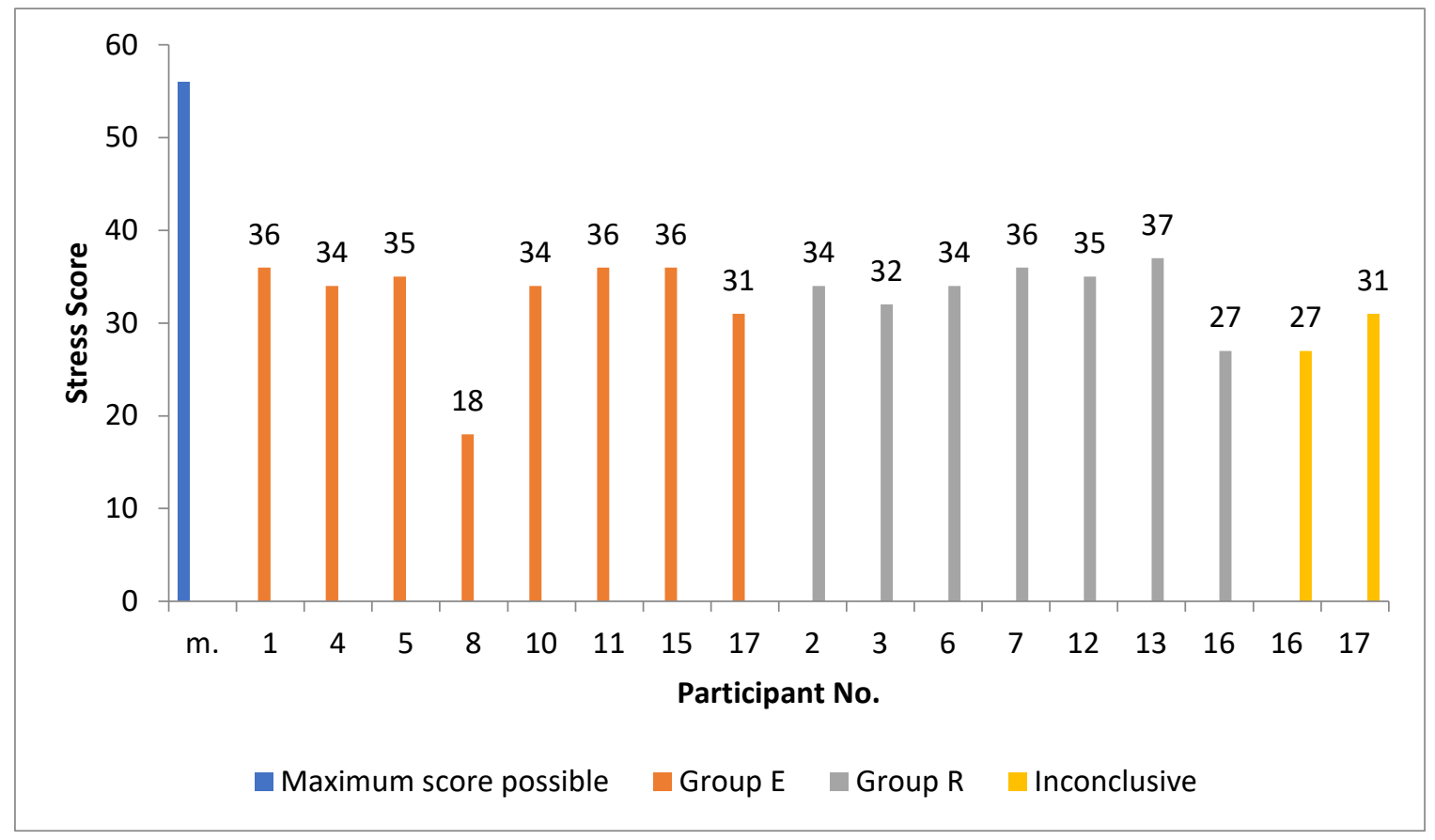

Figure 4: Individual Participant PSS scores and groupings
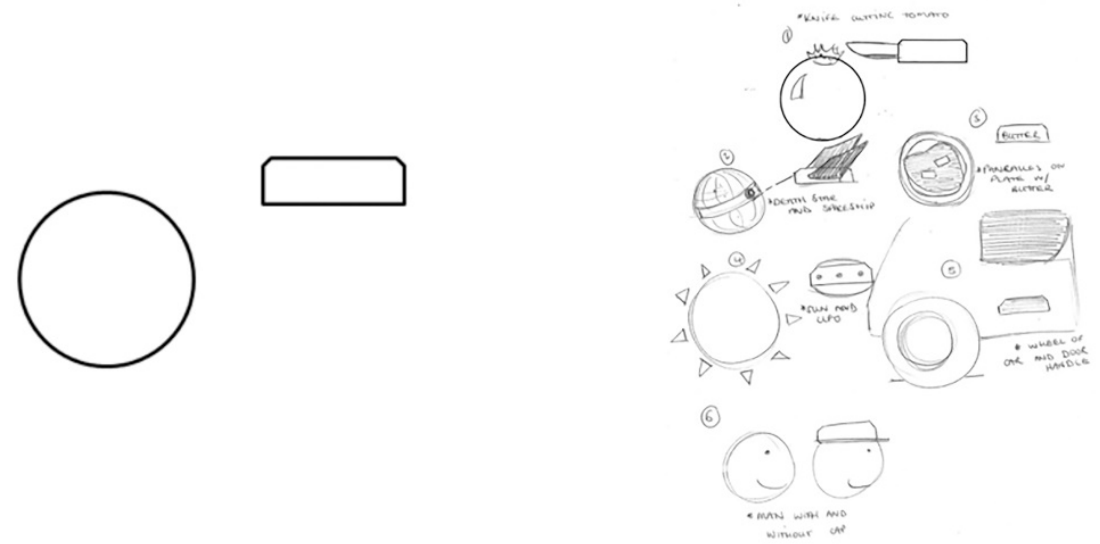

Figure 5: Phase 1 start geometry and associated creative expansion
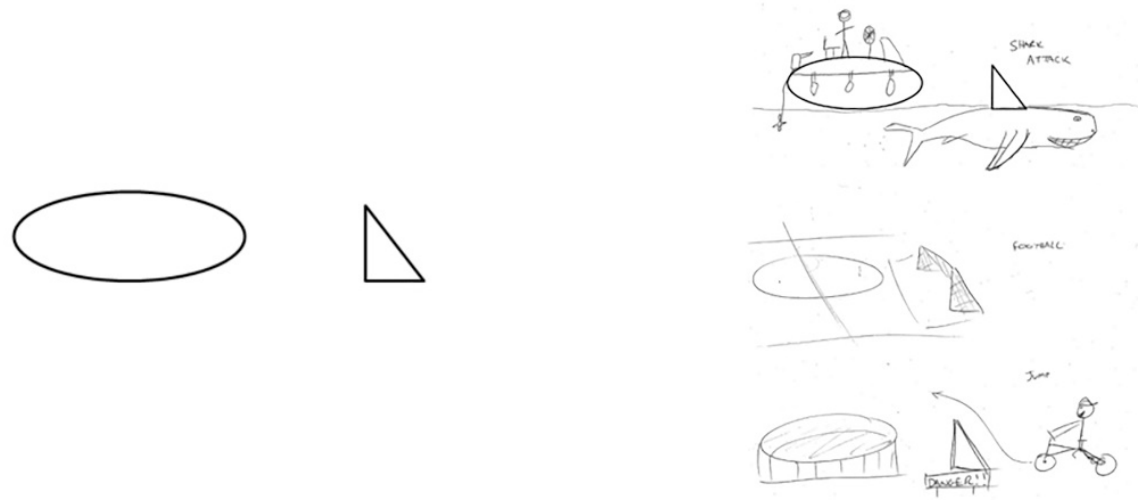


\begin{tabular}{|c|c|c|c|c|c|c|c|c|c|c|}
\hline \multirow[b]{2}{*}{ P. No } & \multicolumn{2}{|c|}{ Fluency } & \multicolumn{2}{|c|}{ Originality } & \multicolumn{2}{|c|}{ Flexibility } & \multicolumn{2}{|c|}{ Elaboration } & \multicolumn{2}{|c|}{ Total } \\
\hline & $\begin{array}{c}\text { Phase } \\
1\end{array}$ & $\begin{array}{c}\text { Phase } \\
2\end{array}$ & $\begin{array}{c}\text { Phase } \\
1\end{array}$ & $\begin{array}{c}\text { Phase } \\
2\end{array}$ & $\begin{array}{c}\text { Phase } \\
1\end{array}$ & $\begin{array}{c}\text { Phase } \\
2\end{array}$ & $\begin{array}{c}\text { Phase } \\
1\end{array}$ & $\begin{array}{c}\text { Phase } \\
2\end{array}$ & $\begin{array}{c}\text { Phase } \\
1\end{array}$ & $\begin{array}{c}\text { Phase } \\
2\end{array}$ \\
\hline \multicolumn{11}{|l|}{ Group R } \\
\hline 2 & 4 & 4 & 2 & 2 & 2 & 1 & 2 & 2 & 10 & 9 \\
\hline 3 & 3 & 2 & 3 & 1 & 4 & 1 & 4 & 2 & 14 & 6 \\
\hline 6 & 3 & 3 & 3 & 3 & 2 & 2 & 3 & 2 & 11 & 11 \\
\hline 7 & 2 & 2 & 4 & 2 & 2 & 2 & 2 & 2 & 10 & 8 \\
\hline 12 & 3 & 1 & 5 & 1 & 4 & 1 & 4 & 3 & 16 & 6 \\
\hline Total & 15 & 12 & 17 & 9 & 14 & 7 & 16 & 11 & 62 & 39 \\
\hline \multicolumn{11}{|l|}{ Group E } \\
\hline 1 & 3 & 3 & 2 & 3 & 1 & 2 & 3 & 2 & 9 & 10 \\
\hline 4 & 2 & 3 & 2 & 2 & 1 & 2 & 3 & 2 & 8 & 9 \\
\hline 5 & 4 & 4 & 3 & 3 & 4 & 4 & 2 & 2 & 13 & 13 \\
\hline 11 & 5 & 4 & 3 & 2 & 3 & 2 & 4 & 2 & 15 & 11 \\
\hline 17 & 3 & 4 & 3 & 2 & 3 & 2 & 2 & 2 & 11 & 10 \\
\hline Total & 17 & 18 & 13 & 12 & 12 & 12 & 14 & 10 & 56 & 53 \\
\hline
\end{tabular}

Figures $5 \& 6$ illustrate the starting geometries and examples of participant's graphical work in response to the request to develop a creative interpretation. Participants were not made aware of the marking criteria.

In the first phase, the results were of a similar standard for both groups, with the differentiation between the two groups overall creativity score being +6 for Group $R$.

\section{Phase 1 Fluency}

The marks for fluency at this stage were relatively uniform across the two groups during the baseline test. The modal score was 3 across both groups with individual high scores recorded on both sides.

\section{Phase 2 Fluency}

The marks for fluency showed the largest gap between the two groups in the second round. Group $R$ performed considerably lower than Group E, with the modal score for the Group $R=2$, in comparison to Group $E=4$.

\section{Phase 1 Originality}

Originality showed a slightly higher score within Group R, with common an obvious themes such as human like figures and planets generally being avoided.

\section{Phase 2 Originality}

Group E performed at a higher level with regards to originality. Group R showed a pattern of keeping to common themes which surfaced several times; these included birds and cups. 


\section{Phase 1 Flexibility}

Flexibility scores were relatively uniform with a deviation of marks between the two groups being recorded as 2 in favour of Group R. Group R showed a slightly higher ability to move away from themes they had already presented within their responses. Common themes displayed more by Group $E$ included human like figures and planets.

\section{Phase 2 Flexibility}

The marks awarded for flexibility displayed a relatively large difference between the groups. There was a 5 point score difference between the two groups in favour of Group E, with Group R displaying a tendency to stick to a theme they had initial conceived and not stray from it in the rest of their responses.

\section{Phase 1 Elaboration}

Elaborative marks were of an average standard across both groups, with Group $\mathrm{R}$ attaining a slightly higher score by giving more detail in their responses than Group E.

\section{Phase 2 Elaboration}

Elaboration was the only section where Group R displayed a higher level of creative ability, however marks were not dissimilar between the two groups.

\section{Comparative Summary}

In Phase 2 the trends were of a notably different standard for both groups, with the differentiation between the two groups overall creativity score being +13 in favour of Group E. Figure 7 shows how Group R scored slightly higher in the first round, but then dropped below Group E's score at the end of the second round.

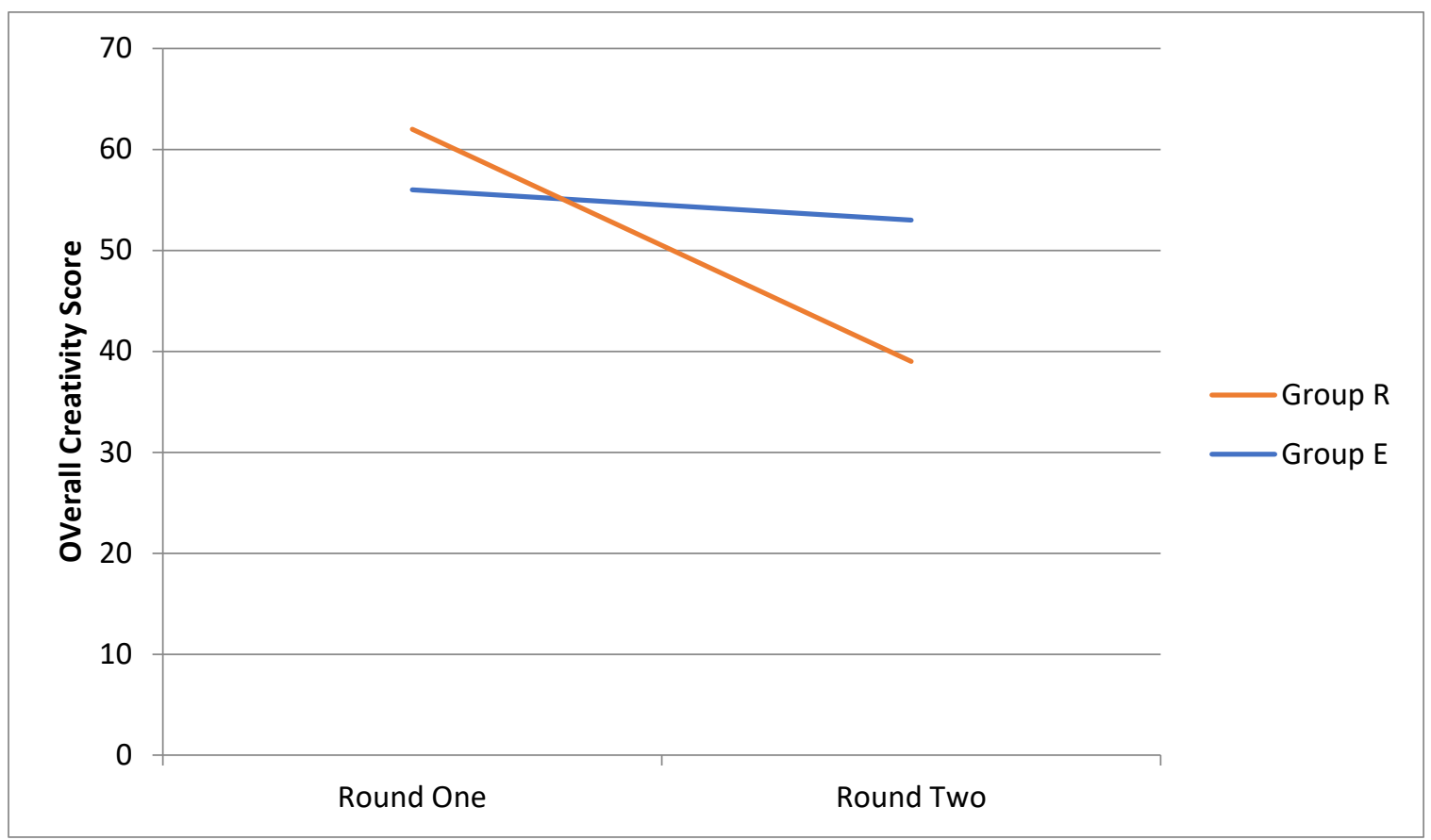

Figure 7: Creativity / Time group performance comparison

\section{Discussion}

It is well debated in current literature that stress is a criterion which has the potential to limit creativity, but subject to various factors including environmental and reactive tolerance. The results of the PSS section suggest that the participants may fit into a stressed category, with relatively high PSS scores recorded across 
all questions by most respondents indicating they were at possible risk of having their creative potential impacted upon. When examining specific answers to the PSS, a trend is apparent that is consistent with students who are displaying negative psychometric thought patterns. Over $70 \%$ of respondents to the survey stated that they felt 'nervous and stressed' either 'fairly often' or 'very often' over the last month. When referring to recent studies such as that conducted by Hsiao et al. (2017), which found that long term stress is incompatible with creativity, the findings from this section of the questionaire alone point towards a situation where students may be at risk having their creativity stifled.

Question 12 (Fig. 3) of the PSS corroborates the theme of high mental stress among the participants. Over $80 \%$ of respondants answered that they were thinking about the things they have to accomplish either 'very often' or 'fairly often'. Hoeever, this may be indicative of a high intensity set of activities within a prescribed education programme with numerous concurrent tasks; and it is also arguable that this may not necessarily be negative behaviour, but a display of a proactive approach to time management.

The grouping stage of the questionnaire (Q15-24) was designed to divide respondents into groups who were more negatively affected by either their environment (Group E), or their reaction to stress (Group R). In general, the responses from the questionnaire gave rise to a marginal division in the participants regarding which determining factor they aligned with more closely. However, some responses suggest there is a degree of crossover, where participants indicated they may be affected by both the environmental stressors and their own negative reactions. For example, questions aimed at gaining insight of environmentally negative affect for the respondents yielded inconclusive responses. Eight participants, who identified as being influenced by the environment (Table 3), also responded that they feel they are not on top of their workload most of the time. This suggests that some of the participants who fitted into the bracket of being more influenced by their reactions still felt influenced to an extent by this particular environmental stressor.

This observation was furthered by responses to questions aimed at probing the participant's attitudes towards being more negatively affected by their reaction to stress possibly even threatened (Gutnick et al., 2012). When asked whether participants wanted to do well at university because it a) will determine their degree (environmental stress as a threat) or b) because they want to challenge themselves, nearly $70 \%$ of the participants sided with the answer that relates to being affected by their environment, a far higher percentage than the overall percentage of participants who were identified as being more influenced by their reaction.

From the results of the figural TTCT, within the context of this small scale study, both groups experienced a decline in creativity over the time period, however Group R displayed a much steeper drop off in creativity.

\section{Summary of Group E}

Although Group E was evaluated as having a drop off in creative output over the time period, it was not perceived to be as pronounced as Group R. A reduction in creativity due to environmental factors may have been logical to expect prior to the results. It is reasonable to suggest that the increase in time pressure may act as a catalyst for the environmental factors limiting the groups creative output. For example, a lack of time to relax, a known key environmental stressor (Ding et al., 2014) would in theory be exacerbated by an increase in time-pressure. Moreover, when considering creativity related to the size of the task at hand, it may be reasonable to expect this group's creativity to diminish as expectations of the students increased over the time period between the two tests.

With environmental stressors, it is possible to experience long term effects rather than purely immediatereactive. For example, the negative outcome from a long term demand for creativity, as set out by $\mathrm{Hsiao}$ et al. (2017), could have been in place for the participant's entire university career. It is possible that over a twoweek period alone there may not have been large fluctuations in levels of the participants' creativity at this particular stage. Furthermore, when considering the evaluative nature of Group E's collective diminishing creativity, the participants who were identified as being more influenced by environmental stressors have been in the evaluative environment since the beginning of their university career. Although it is arguable that the evaluative nature has become more important in the final year of their study, it has not changed in format since they started.

\section{Summary of Group $R$}

Regardless of whether or not Group E would perform better outside of their creative constraints, the results here have indicated that Group R appeared to reach a relatively lower standard of creativity overall as time- 
pressure increased. Superficially the results suggest that participants who identified as being more affected by their adverse reactions to stress, may suffer more with regards to creative output. Factors such as lack of motivation (Ceci \& Kumar, 2016) and viewing work as a threat (Gutnick et al., 2012) are much more dynamic than the environmental factors, and may also be more sporadic and unpredictable. For example, lack of motivation affecting creativity may be described as a phenomenon which is short term and variable rather than a key environmental factor such as long term demand for creativity (Hsiao et al., 2017).

The results of the TTCT lean towards an agreement with various studies that suggest an individual's reactions to stress dictate possible negative effects on creativity more so than environmental stressors. For example, in terms of personality traits and creativity, Baas et al. (2013) describe how individuals who react negatively to stress by losing mental stamina are less likely to attain a high level of creative output. As the participants were under considerable pressure for the weeks before and between the baseline and repeat tests, it may well have reduced the participants' mental stamina.

The results found in the TTCT further add to the suggestion of a lack of motivation leading to a lower calibre of creative output. As to whether or not the students' motivation influenced the results is debatable, however, when referencing both the results of the questionnaire and TTCT, there appears to be some connection between the participants who said they were less motivated, and those who scored lower on the TTCT. From the assessor's view there was a drop off in originality and elaboration in Group R. There were many consistent themes displayed in the answers of this group such as cups and birds, as well as a distinct lack of elaboration in many answers. Lack of motivation could be a logical explanation for this result, as the participants would be required to exert intrinsic motivation to conceptualise original ideas in a reasonable amount of detail.

Further possible explanations for the drop in creativity from Group R may come from the theme of evaluative circumstances impairing an individual's creative abilities as described by Byron et al. (2010). Prior to the tests being completed the participants were given an overview of the research and thus understood that their work would be under scrutiny once they had submitted responses. From the questionnaire it was clear to see that many participants from Group R suggested that they saw university as a system that evaluated them rather than taught and supported them. The results of the TTCT appear to support this argument from Byron (ibid.) and provide a further possible explanation as to why Group R appears to have had their creativity limited much more than the Group E as time-pressure increased.

\section{Discussion in context}

The relationship between stress and creativity is particularly poignant for educational institutions and professional organisations in the so called 'creative industries'. From the initial observations of this study it could be suggested that at present, practices are failing to enable some Design students to reach their creative potential by not recognising the barriers to creativity.

Some may argue that dealing with stress when creativity is demanded holds the key to being successful in the creative industries. Increasingly, educational establishments are strengthening their industry links, and it is arguable that stress does not dissipate as a student transitions from university life into a career. There are still deadlines to meet, there are professional creative requirements to be met, and there are environments strongly resembling that of university institutions or vice versa.

With that in mind, it is also debatable that whilst the stress within educational institutions may not be conducive to cultivating creativity in students, it is unavoidable. Preparing students for a realistic career in industry may be viewed as being just as important as sharpening their creative talent. This comes with the counter argument that if students are given the optimum circumstances to be able to grow their inherent creativity, this will make them far more employable than simply getting them used to working in high pressure scenarios.

The work here provides the briefest of insights into the link between creativity and induced stress, from environmental and reactive sources. Indications are that at university level, the environment invoke and its students can develop symptoms of these stressors with the inevitable effects on creativity levels. While there are some that maintain universities are a place to learn in a relatively low risk environment, others drive the notion that a university is a proving ground for industry. The Design profession is particularly susceptible to this dichotomy. 


\section{Limitations and further work}

The limitations of this work relates to timing and scale. The timings in assessing participants may be crucial as there are continual peaks and troughs in demands of work throughout the year. Not all participants will be subject to the same deadlines and there are individual differences in time management skills and organisational ability will skew results, especially where there are low numbers of participants. With regards to the TTCT, it would have been ideal to, a) perform the tests further apart to allow for a higher increase in time pressure and b) to perform the baseline tests when there was a lower level of stress present in the participants. This would have been particularly useful for the Group $\mathrm{E}$ as their creative constraints may be less dynamic than Group R.

In terms of scale, the low numbers of participants is less convincing as a quantitative survey. To provide clearer evidence of expected relationships and correlation, work needs to continue to study bigger populations across different design programmes. This would support more generic conclusions on creativity but also facilitate subject specify studies.

The specific work presented in this paper has not dealt in depth with the myriad of issues surrounding creativity, behaviours and performance. There are many additional issues including; subject specificity, risk taking, research and exploratory failure and the nurturing of creative confidence. Personal traits, motivation, learning styles and fear of negative evaluation, are all areas that are open to investigation to gain further insight into the nature of stress related creativity.

\section{Conclusion}

The results of the questionnaire suggest that student participants of this survey were generally under a high level of stress, and may be primed to have their creativity limited as a consequence. Although overall there is a suggested divide between individuals who may be more influenced by either the environmental stressors or their own reaction to stress, the points of crossover between the groups suggest the relationship is more complex than previously outlined in the literature. In this case, the TTCT results suggest that individuals who are more affected by their negative reactions to stress are more likely to have their creativity negatively affected than those who are more influenced by the environment.

\section{References}

Amabile, T., Hadley, C., \& Kramer, S. (2002). Creativity under the gun. Harvard Business Review.

Amabile, T. M. (1979). Effects of external evaluation on artistic creativity. Journal of Personality and Social Psychology, 37(2), 221-233. http://doi.org/10.1037/0022-3514.37.2.221

Amabile, T. M. (1983). The social psychology of creativity: A componential conceptualization. Journal of Personality and Social Psychology, 45(2), 357-376. http://doi.org/10.1037/0022-3514.45.2.357

Andrews, R. A. N. K. M., \& Farris, G. F. (1972). Time Pressure and Performance of Scientists and Engineers : A Five-Year Panel Study 1, 200, 185-200.

Baas, M., Roskes, M., Sligte, D., Nijstad, B. A., \& De Dreu, C. K. W. (2013). Personality and creativity: The dual pathway to creativity model and a research agenda. Social and Personality Psychology Compass, $7(10)$, 732-748. http://doi.org/10.1111/spc3.12062

Bandura, A. (1993). Perceived Self-Efficacy in Cognitive Development and Functioning. Educational Psychologist, 28(2), 117-148. http://doi.org/10.1207/s15326985ep2802_3

Byron, K., Khazanchi, S., \& Nazarian, D. (2010). The Relationship Between Stressors and Creativity: A MetaAnalysis Examining Competing Theoretical Models. Journal of Applied Psychology, 95(1), 201-212. http://doi.org/10.1037/a0017868

Carnevale, P. J., \& Probst, T. M. (1998). Social Values and Social Conflict in Creative Problem Solving and Categorization, (5), 1300-1309.

Ceci, M. W., \& Kumar, V. K. (2016). A Correlational Study of Creativity, Happiness, Motivation, and Stress from Creative Pursuits. Journal of Happiness Studies, 17(2), 609-626. http://doi.org/10.1007/s10902-0159615-y 
Cohen, R. A. (2011). Yerkes-Dodson Law. In Encyclopedia of Clinical Neuropsychology. http://doi.org/10.1007/978-0-387-79948-3_1340

Cohen, S., Kamarack, T., \& Mermelstein, R. (1983). A Global Measure of Perceived Stress. Health and Social Behaviour, 24(No. 4), 385-396.

Ding, X., Tang, Y. Y., Tang, R., \& Posner, M. I. (2014). Improving creativity performance by short-term meditation. Behavioral and Brain Functions, 10(1), no pagination. http://doi.org/10.1186/1744-9081-109

Friedman, M. . (2014). Creativity and Psychological Well-being. Contemporary Readings in Law and Social Justice, 6(2), 39-58.

Griffin, M., \& McDermott, M. (1998). Exploring a tripartite relationship between rebelliousness, openness to experience, and creativity m, 26(4), 347-356. http://doi.org/10.2224/sbp.1998.26.4.347

Gutnick, D., Walter, F., Nijstad, B. A., \& De Dreu, C. K. W. (2012). Creative performance under pressure: An integrative conceptual framework. Organizational Psychology Review, 2(3), 189-207. http://doi.org/10.1177/2041386612447626

Hsiao, S. W., Wang, M. F., \& Chen, C. W. (2017). Time pressure and creativity in industrial design. International Journal of Technology and Design Education, 27(2), 271-289. http://doi.org/10.1007/s10798-015-9343-y

Kelley, T. (2001). The Art of Innovation: Lessons in Creativity from IDEO, America's Leading Design Firm. Journal of Product Innovation Management. http://doi.org/10.1111/j.1540-5885.2012.01009.x

Leung, K., Huang, K.-L., Su, C.-H., \& Lu, L. (2011). Curvilinear relationships between role stress and innovative performance: Moderating effects of perceived support for innovation. Journal of Occupational and Organizational Psychology, 84(4), 741-758. http://doi.org/10.1348/096317910X520421

Liu, L., Wang, L., Ren, J., \& Liu, C. (2017). Promotion/prevention focus and creative performance: Is it moderated by evaluative stress? Personality and Individual Differences, 105, 185-193. http://doi.org/10.1016/j.paid.2016.09.054

McCardle, J. R., Huskisson, A., \& Perry, S. (2018). Performance Metrics: are the risks too high to be creative? In Engineering and Product Design Education. Design Society.

Nguyen, T. A., \& Zeng, Y. (2012). A theoretical model of design creativity: Nonlinear design dynamics and mental stress-creativity relation. Journal of Integrated Design and Process Science, 16(3), 65-88. http://doi.org/10.3233/jid-2012-0007

Oldham, G. R., \& Cummings, A. (1996). Employee creativity: Personal and contextual factors at work. Academy of Management Journal. http://doi.org/10.2307/256657

Phelan, S., \& Young, A. M. (2003). Understanding creativity in the workplace: An examination of individual styles and training in relation to creative confidence and creative self-leadership. Journal of Creative Behavior. http://doi.org/10.1002/j.2162-6057.2003.tb00994.x

Shalley, C. E., \& Perry-Smith, J. E. (2001). Effects of social-psychological factors on creative performance: The role of informational and controlling expected evaluation and modeling experience. Organizational Behavior and Human Decision Processes, 84(1), 1-22. http://doi.org/10.1006/obhd.2000.2918

Shalley, C. E., Zhou, J., \& Oldham, G. R. (2004). The effects of personal and contextual characteristics on creativity: Where should we go from here? Journal of Management. http://doi.org/10.1016/j.jm.2004.06.007

Sternberg, R. J. (2010). The Nature of Creativity The Nature of Creativity. Creativity Research Journal, 18(1), 87-98. http://doi.org/10.1207/s15326934crj1801 10

Sung, S. Y., \& Choi, J. N. (2009). Do Big Five Personality Factors Affect Individual Creativity? the Moderating Role of Extrinsic Motivation. Social Behavior and Personality: An International Journal. http://doi.org/10.2224/sbp.2009.37.7.941

Wallach, A. M. (1968). Review: Torrance Tests of Creative Thinking: Norms - Technical Manual by E. Paul Torrance. American Educational Journal, 5(2), 272-281. 
Wilke, P. ., Gmelch, W. ., \& Lovrich, N. . (1985). Stress and Productivity:Evidence of the Inverted U Function. Public Productivity Review, 9(4), 342-356. http://doi.org/10.2307/3379944 